\title{
DEJETO LÍQUIDO BOVINO EM PLANTIO DIRETO: PERDA DE CARBONO E NITROGÊNIO POR ESCOAMENTO SUPERFICIAL ${ }^{(1)}$
}

\author{
Fabiana de Medeiros Silveira ${ }^{(2)}$; Nerilde Favaretto ${ }^{(3)}$, Jeferson \\ Dieckow $^{(3)}$, Volnei Pauletti ${ }^{(3)}$, Fabiane Machado Vezzani ${ }^{(3)} \&$ Eder \\ David Borges da Silva ${ }^{(4)}$
}

\begin{abstract}
RESUMO
A utilização de dejetos de animais na produção agrícola é uma alternativa de disposição do resíduo gerado na atividade pecuária, porém se aplicado inadequadamente pode causar problemas ambientais. Nesse sentido, o objetivo geral deste trabalho foi avaliar as concentrações e perdas de $\mathrm{C} \mathrm{e} \mathrm{N}$ por escoamento superficial em quatro doses de dejeto líquido bovino $\left(0,60,120,180 \mathrm{~m}^{3} \mathrm{ha}^{-1} \mathrm{ano}^{-1}\right)$ aplicado em Latossolo franco-argiloarenoso com $13 \%$ de declividade, manejado em plantio direto com soja, aveia-preta, milho e trigo, em sistema de rotação. $O$ escoamento superficial foi coletado durante dois anos e sete meses em galões de $60 \mathrm{~L}$ após cada chuva, com geração de escoamento em pelo menos uma parcela. Os nutrientes solúveis foram determinados em amostra filtrada por uma membrana de éster de 0,45 $\mu \mathrm{m}$ e os nutrientes totais, em amostras não filtradas. A aplicação de dejeto líquido bovino reduziu as perdas de $\mathrm{C}$ orgânico e $\mathrm{N}$ por escoamento superficial, com consequências positivas para a qualidade da água em corpos hídricos a jusante. Porém, doses crescentes de dejeto tendem a aumentar a concentração dos referidos elementos e, por conseguinte, diminuir a qualidade da água. As concentrações médias ponderadas de nitrato estiveram abaixo do limite permitido pela legislação brasileira, porém as de amônio ficaram acima do máximo permitido, indicando a necessidade de práticas de controle e retenção do escoamento superficial, a fim de evitar a entrada do nitrato nos corpos d'água, mesmo em áreas sob plantio direto. Cabe ressaltar que esses dados foram obtidos em condição de baixo potencial poluidor, ou seja, relevo com $13 \%$ de declividade,
\end{abstract}

\footnotetext{
(1) Parte da Dissertação de Mestrado da primeira autora apresentada ao Programa de Pós-Graduação em Ciência do Solo da Universidade Federal do Paraná - UFPR. Recebido para publicação em 15 de julho de 2010 e aprovado em 11 de agosto de 2011.

(2) Professora Substituta do Departamento de Solos e Engenharia Agrícola, Universidade Federal do Paraná - UFPR. Rua dos Funcionários 1540, CEP 80035-050 Curitiba (PR). E-mail: biafabbrin@yahoo.com.br

${ }^{(3)}$ Professores do Departamento de Solos e Engenharia Agrícola, UFPR. E-mails: nfavaretto@ufpr.br; jefersondieckow@ufpr.br; vpauletti@ufpr.br; vezzani@ufpr.br

(4) Aluno de Agronomia da UFPR. Bolsista do CNPq/PIBIC. E-mail: ederdbs@gmail.com
} 


\begin{abstract}
baixa precipitação e intervalo mínimo de dez dias entre a aplicação do dejeto e a ocorrência de chuva, com formação de escoamento superficial. Além disso, há a necessidade de estudos futuros para avaliar a lixiviação de nitrato.
\end{abstract}

Termos de indexação: erosão hídrica, adubação orgânica, qualidade de água, nutrientes, amônio, nitrato.

\title{
SUMMARY: LIQUID DAIRY MANURE IN NO-TILL: CARBON AND NITROGEN LOSS BY RUNOFF
}

\begin{abstract}
The use of manure in agricultural system is a possibility to dispose of the waste generated in animal production, but improper use can cause environmental problems. The general objective of this study was to evaluate carbon and nitrogen concentrations and losses in runoff in four doses of liquid dairy manure $\left(0,60,120,180 \mathrm{~m}^{3} \mathrm{ha}^{-1} \mathrm{yr}^{-1}\right)$ applied to a silt clay loam Oxisol with $13 \%$ slope, in no-till with soybean, oat, corn, and wheat in crop rotation. The runoff was collected for two years and seven months in $60 \mathrm{~L}$ containers after every rain with runoff from at least one plot. Soluble nutrients were analyzed in runoff samples filtered through a 0.45 ??ìm membrane and total nutrients in unfiltered samples. The application of liquid dairy manure reduced the losses of organic carbon and nitrogen, with positive consequences for water quality. However, higher rates tended to increase the concentrations of these elements and, consequently, reduce water quality. The weighted average concentrations of nitrate were below the limit allowed by Brazilian legislation, but ammonium exceeded the threshold values, indicating the need of control measures to prevent the runoff from reaching the water bodies, even in no-tillage systems. It should be pointed out that these data were obtained under low potential polluting conditions, i.e, on $13 \%$ slope, low rainfall and with a minimum interval of ten days between manure application and rainfall. Further studies should also evaluate nitrate leaching.
\end{abstract}

Index terms: water erosion, organic fertilization, water quality, nutrients, ammonium, nitrate.

\section{INTRODUÇÃO}

A região dos Campos Gerais no Estado do Paraná destaca-se na bovinocultura leiteira em sistema semiconfinado, no qual o dejeto líquido produzido vem sendo aplicado na produção de grãos em plantio direto, no entanto sem critérios técnicos bem definidos. A aplicação de resíduos traz benefícios ao sistema produtivo, em razão da adição de nutrientes e matéria orgânica no solo. No entanto, em contrapartida existe a preocupação sobre o potencial poluidor nas águas superficiais e subterrâneas (Smith et al., 1990; Scherer \& Aita, 1996; Hooda et al., 2000).

Elevadas concentrações de nutrientes, especialmente $\mathrm{P}, \mathrm{N}$ e $\mathrm{C}$ na água, podem causar danos ambientais e à saúde humana e animal. O P e o N estão associados ao problema de eutrofização, no entanto o P é considerado o elemento limitante, porque o N pode ser fornecido via fixação do $\mathrm{N}$ atmosférico por algumas plantas aquáticas (Correll, 1998; Daniel et al., 1998).

O N, além da eutrofização, está associado a problemas com saúde humana, como a síndrome do bebê-azul ou meta-hemoglobinemia, alteração na oxigenação do sangue causada pelo nitrato $\left(\mathrm{NO}_{3}^{-}\right)$. O nitrato também tem sido associado a doenças cancerígenas (Smith et al., 1990). O íon amônio $\left(\mathrm{NH}_{4}{ }^{+}\right)$, que é convertido em amônia $\left(\mathrm{NH}_{3}{ }^{+}\right)$e viceversa, em função do $\mathrm{pH}$ (Sparks, 1995), pode alterar a vida aquática, pois os animais aquáticos são muito sensíveis à toxidez de amônia $\left(\mathrm{NH}_{3}{ }^{+}\right)$(Smith et al., 1990; Dinnes et al., 2002).

Com relação ao C orgânico, adições excessivas podem causar o rápido crescimento de microrganismos, que resultará em elevada demanda bioquímica de oxigênio e, consequentemente, diminuição do oxigênio dissolvido, afetando a vida aquática (Hooda et al., 2000). Além disso, a presença de C orgânico solúvel é preocupante devido à formação de tri-halometanos, compostos cancerígenos, durante o processo de cloração em sistemas de tratamento de água para abastecimento humano (Kay et al., 2009).

No Brasil, a Resolução CONAMA 357/2005 do Conselho Nacional do Meio Ambiente (Brasil, 2005) regula o nível máximo de poluentes nas águas superficiais de acordo com o uso previsto, enquanto a Portaria 518/2004 do Ministério da Saúde (Brasil, 2004) regula a qualidade da água para consumo humano.

No escoamento superficial, o $\mathrm{N}$ divide-se em duas formas, solúvel e particulada. A forma solúvel é 
constituída pelo $\mathrm{N}-\mathrm{NO}_{3}^{-}$e $\mathrm{N}-\mathrm{NH}_{4}^{+}$, sendo imediatamente disponível à vida aquática. Já a forma particulada, que corresponde à fração que se encontra adsorvida às partículas sólidas do solo ou, ainda, como constituinte das partículas orgânicas do solo, representa uma fonte de longo prazo (Sharpley et al., 1987). Para o $\mathrm{N}$ na forma de $\mathrm{N}-\mathrm{NO}_{3}{ }^{-}$, a lixiviação é o principal processo envolvido no transporte desse íon do solo para a água devido à baixa capacidade de retenção, na maioria dos solos (Eghball \& Gilley, 1999). No entanto, perdas elevadas de $\mathrm{N}_{-} \mathrm{NO}_{3}{ }^{-} \mathrm{em}$ superfície podem ocorrer, especialmente em eventos de precipitação logo após a aplicação de fertilizantes, tanto na forma orgânica quanto na forma mineral (Bertol et al., 2005; Mori, 2008). Embora as perdas de $\mathrm{N}_{-} \mathrm{NO}_{3}{ }^{-}$via superfície geralmente sejam pequenas (Smith et al., 2001a), outras formas de N, como N$\mathrm{NH}_{4}{ }^{+}$e $\mathrm{N}$ particulado, podem representar perdas significativas via escoamento superficial (Hooda et al., 2000). Nos dejetos líquidos, além do $\mathrm{N}$ orgânico, a principal forma de $\mathrm{N}$ solúvel encontrada é o $\mathrm{N}_{-} \mathrm{NH}_{4}{ }^{+}$, apesar de haver grande variação em função de vários fatores, como idade dos animais, tipo de alimentação e sistema de manejo (Hooda et al., 2000).

A expectativa com relação ao incremento de doses de dejeto animal é de que a concentração e a quantidade perdida de $\mathrm{C}$ e $\mathrm{N}$ via escoamento superficial aumente. Aplicações sucessivas de adubos orgânicos e inorgânicos elevam as concentrações dos nutrientes no solo, aumentando, assim, o potencial de transporte de nutrientes do solo para a água (Scherer \& Aita, 1996; Schick et al., 2000; Bertol et al., 2003), fato que se agrava no sistema plantio direto, devido à não incorporação dos fertilizantes (Schick et al., 2000). Sabe-se que o sistema plantio direto é muito eficiente no controle das perdas de solo, mas, também, que os solos apresentam capacidade máxima de infiltração e que, mesmo em plantio direto, após esse limite o escoamento, associado a poluentes, irá ocorrer (Cogo et al., 1996; Bertol et al., 1997; Mello et al., 2003).
Experimentos de curta duração, com chuvas logo após a aplicação de dejeto líquido, têm mostrado maiores perdas de solo, água e nutrientes (Bertol et al., 2005, 2007; Allen \& Mallarino, 2008; Mori et al., 2009), possivelmente em função do selamento superficial causado pelo material orgânico. No entanto, experimentos de longa duração indicam menores perdas de solo, água e nutrientes (Bundy et al., 2001; Smith et al., 2001a,b), em razão dos efeitos benéficos do dejeto na qualidade física do solo, diminuindo o escoamento superficial.

Dentro desse contexto, o objetivo foi analisar o potencial poluidor do dejeto líquido bovino aplicado na superfície do solo no sistema plantio direto. Avaliaramse a concentração e quantidade perdida por escoamento superficial de $\mathrm{C}$ e $\mathrm{N}$ sob chuva natural, em Latossolo de textura franco-argiloarenoso, na região dos Campos Gerais, no Estado do Paraná.

\section{MATERIAL E MÉTODOS}

\section{Instalação do experimento de campo}

O trabalho foi conduzido na Estação Experimental da Fundação ABC, localizada em Ponta Grossa, PR, na região dos Campos Gerais. O clima da região é o subtropical úmido, do tipo $\mathrm{Cfb}$, e a precipitação média anual é de $1.554 \mathrm{~mm}$ (Caviglione et al., 2000). O solo é classificado como Latossolo Vermelho-Amarelo distrófico típico (Embrapa, 2001), cujos atributos físicos e químicos (Mori, 2008) são apresentados nos quadros 1 e 2 .

O experimento foi instalado em novembro de 2005, em uma área com $13 \%$ de declividade, a qual vinha sendo adubada exclusivamente com fertilizantes minerais em sistema de rotação com soja, milho, trigo e aveia, sob plantio direto há mais de 12 anos.

Quadro 1. Atributos físicos do solo da área experimental na profundidade de 0 a $20 \mathrm{~cm}$

\begin{tabular}{|c|c|c|c|c|c|c|c|}
\hline \multirow{2}{*}{ Argila } & \multirow{2}{*}{ Silte } & \multirow{2}{*}{ Areia } & \multirow{2}{*}{$D S^{(1)}$} & \multirow{2}{*}{$\mathrm{DMP}^{(2)}$} & \multirow{2}{*}{$\mathrm{CH}^{(3)}$} & \multicolumn{2}{|c|}{ Porosidade } \\
\hline & & & & & & Micro & Macro \\
\hline 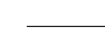 & $-\mathrm{g} \mathrm{kg}^{-1}$ & - & $\mathrm{kg} \mathrm{dm}-3$ & $\mathrm{~mm}$ & $\mathrm{~mm} \mathrm{~h}^{-1}$ & 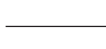 & 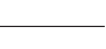 \\
\hline 228 & 33 & 739 & 1,5 & 1,33 & 47 & 28 & 15 \\
\hline
\end{tabular}

(1) DS: Densidade do Solo. ${ }^{(2)}$ DMP: Diâmetro Médio Ponderado dos Agregados. ${ }^{(3)} \mathrm{CH}$ : Condutividade Hidráulica Saturada.

Quadro 2. Atributos químicos do solo da área experimental na profundidade de 0 a $20 \mathrm{~cm}$

\begin{tabular}{|c|c|c|c|c|c|c|c|c|c|}
\hline pH $\mathrm{CaCl}_{2}$ & Al & $\mathbf{H}+\mathbf{A l}$ & $\mathrm{Ca}^{2+}$ & $\mathrm{Mg}^{2+}$ & $\mathbf{K}^{+}$ & P (Mehlich-1) & $\mathrm{N}-\mathrm{NH}_{4}^{+(1)}$ & $\mathrm{N}-\mathrm{NO}_{3}^{-(1)}$ & C \\
\hline & - & & $\mathrm{ol}_{\mathrm{c}} \mathrm{dm}$ & & & - & $-\mathrm{mg} \mathrm{dm}^{-3}$ & & $\mathrm{~g} \mathrm{dm}^{-3}$ \\
\hline 5,1 & 0 & 3,5 & 3,7 & 0,7 & 0,17 & 19,0 & 14,4 & 17,0 & 13,2 \\
\hline
\end{tabular}

(1) Extraídos em KCl $2 \mathrm{~mol} \mathrm{~L}^{-1}$. 
Os tratamentos consistiram de quatro doses de dejeto líquido bovino (0, 60, 120 e $\left.180 \mathrm{~m}^{3} \mathrm{ha}^{-1} \mathrm{ano}^{-1}\right)$, distribuídos em delineamento experimental de blocos ao acaso com quatro repetições, totalizando 16 parcelas experimentais. O dejeto foi aplicado em duas épocas, metade no verão e metade no inverno, sobre a superfície do solo com regadores manuais, nas entrelinhas das culturas, após a semeadura. A procedência do dejeto foi de uma propriedade produtora de gado leiteiro em sistema de confinamento, coletado diretamente da esterqueira. Os atributos foram caracterizados, sendo eles os dados médios e o desviopadrão do dejeto aplicado nas cinco épocas (verão/2005; inverno e verão/2006; e inverno e verão 2007): 70,6 $( \pm 34,6) \mathrm{g} \mathrm{L}^{-1}$ de amostra seca, $1,61( \pm 0,75) \mathrm{g} \mathrm{L}^{-1} \mathrm{de}$ nitrogênio total, $0,60( \pm 0,23) \mathrm{g} \mathrm{L}^{-1}$ de fósforo total e $1,68( \pm 0,51) \mathrm{g} \mathrm{L}^{-1}$ de potássio total.

Além da aplicação do dejeto, foram utilizados fertilizantes minerais de acordo com a necessidade da cultura. A utilização de fertilizantes minerais, além da adubação orgânica, é prática comum dos produtores da região, e, portanto, reproduzida neste trabalho. A quantidade de nutrientes aplicada durante todo o período de estudo (cinco safras) encontra-se no quadro 3.

As parcelas experimentais foram alocadas no sentido do declive com dimensões de 3,5 m de largura por $9 \mathrm{~m}$ de comprimento, sendo delimitadas por chapas de metal zincado introduzidas a $5 \mathrm{~cm}$ no solo e com uma borda de $5 \mathrm{~cm}$ acima da superfície, e tendo a extremidade inferior (o último $1 \mathrm{~m}$ ) construída em forma de "V". O escoamento foi canalizado com um tubo de PVC de $75 \mathrm{~mm}$ de diâmetro para um galão de $60 \mathrm{~L}$.

\section{Coleta do escoamento superficial}

As coletas do escoamento superficial ocorreram de novembro de 2005 a maio de 2008, após cada chuva, com ocorrência de escoamento superficial em no mínimo uma parcela. Nesse período, aconteceram 37 eventos de chuva natural com coleta de escoamento, porém o número total de parcelas coletadas foi de apenas 279 amostras, isso porque, em vários eventos, o escoamento ocorreu em apenas algumas parcelas.
Após a homogeneização do escoamento coletado no galão de $60 \mathrm{~L}$, uma alíquota representativa era acondicionada em garrafas de plástico de $500 \mathrm{~mL}$ e imediatamente congelada.

Considerando a importância do primeiro evento com ocorrência de escoamento após a aplicação do dejeto, pode-se afirmar que nesse experimento isso ocorreu com no mínimo uma semana de intervalo, mais especificamente 10, 29 e 11 dias, no verão 06/07, inverno 07 e verão 07/08, respectivamente. No verão 05/06 e inverno 06, não houve chuvas com escoamento superficial.

Os dados pluviométricos foram coletados em uma estação meteorológica situada a $500 \mathrm{~m}$ do experimento, na FUNDAÇÃO ABC, resultando em um volume de $2.715 \mathrm{~mm}$ no período analisado, ou seja, uma média de $1.050 \mathrm{~mm}^{\mathrm{ano}}{ }^{-1}$.

\section{Análises laboratoriais}

Após o descongelamento das amostras, procedeuse à filtragem, utilizando uma membrana de éster de $0,45 \mu \mathrm{m}$, para a determinação dos nutrientes solúveis. Para análise do C orgânico total, empregaram-se as amostras não filtradas, as quais foram submetidas ao método do refluxo aberto adaptado, conforme Boyd \& Tucker (1992), para determinação da demanda química de oxigênio com cálculo de equivalente em $\mathrm{C}$.

A determinação do $\mathrm{N}-\mathrm{NO}_{3}{ }^{-}$ocorreu por espectrometria com adição de ácido clorídrico, e a do $\mathrm{N}-\mathrm{NH}_{4}{ }^{+}$, pelo método do fenato (Apha, 1995).

A concentração média ponderada foi obtida multiplicando-se a concentração pelo volume de escoamento em cada coleta. Esses produtos foram somados e o resultado dividido pelo volume total de escoamento nos respectivos tratamentos e repetições.

Para a obtenção da perda acumulada, utilizaramse os dados de concentração dos respectivos nutrientes e o volume de escoamento em cada coleta. As perdas em cada coleta foram somadas, obtendo-se, assim, a perda acumulada no período total de avaliação (novembro/2005 a maio/2008).

Quadro 3. Quantidade total de nitrogênio, fósforo e potássio aplicados via dejeto líquido bovino e adubação mineral durante o período experimental, novembro de 2005 a maio de 2008

\begin{tabular}{|c|c|c|c|c|c|c|c|c|c|c|c|}
\hline \multicolumn{3}{|c|}{$0 \mathrm{~m}^{3} \mathrm{ha}^{-1}$ ano $^{-1}$} & \multicolumn{3}{|c|}{$60 \mathrm{~m}^{3} \mathrm{ha}^{-1}$ ano $^{-1}$} & \multicolumn{3}{|c|}{$120 \mathrm{~m}^{3} \mathrm{ha}^{-1} \mathrm{ano}^{-1}$} & \multicolumn{3}{|c|}{$180 \mathrm{~m}^{3} \mathrm{ha}^{-1} \mathrm{ano}^{-1}$} \\
\hline $\mathbf{N}$ & $\mathbf{P}$ & $\mathbf{K}$ & $\mathbf{N}$ & $\mathbf{P}$ & $\mathbf{K}$ & $\mathbf{N}$ & $\mathbf{P}$ & $\mathbf{K}$ & $\mathbf{N}$ & $\mathbf{P}$ & $\mathbf{K}$ \\
\hline \multicolumn{12}{|c|}{ Dejeto líquido bovino } \\
\hline- & - & - & 242 & 89 & 252 & 482 & 178 & 504 & 723 & 268 & 756 \\
\hline \multicolumn{12}{|c|}{ Adubação mineral } \\
\hline 222 & 143 & 138 & 222 & 143 & 138 & 222 & 143 & 138 & 222 & 143 & 138 \\
\hline
\end{tabular}




\section{Análises estatísticas}

Para avaliar o efeito das doses de dejeto líquido bovino na quantidade perdida e na concentração de $\mathrm{C}$ orgânico e N, ajustaram-se modelos de regressão polinomial quadrática, por meio da ferramenta estatística do programa Sigma Plot for Windows (Systat Software, 2006).

\section{RESULTADOS E DISCUSSÃO}

\section{Carbono orgânico total}

A aplicação de $120 \mathrm{~m}^{3} \mathrm{ha}^{-1}$ ano $^{-1}$ de dejeto líquido bovino reduziu em $20 \%$ a concentração média ponderada de C orgânico total (COT) no escoamento superficial em relação ao tratamento sem aplicação de dejeto (Figura 1a). No entanto, para a perda acumulada de COT, a redução foi muito maior (89 \%) com a aplicação de $120 \mathrm{~m}^{3} \mathrm{ha}^{-1} \mathrm{ano}^{-1}$ (Figura 1b), evidenciando-se a vantagem da aplicação de dejeto até a referida dose, a fim de mitigar perdas de $\mathrm{C}$ por escoamento superficial. Entretanto, a maior dose de dejeto $\left(180 \mathrm{~m}^{3} \mathrm{ha}^{-1} \mathrm{ano}^{-1}\right)$ aumentou a concentração em $164 \%$, porém diminui a perda de COT no escoamento em $71 \%$, de forma que o modelo quadrático com ponto de mínima apresentou ajuste satisfatório para a explicação de tais resultados (Figura 1). De acordo com esse ajuste quadrático e igualando sua primeira derivada à zero, obtém-se a dose de $117 \mathrm{~m}^{3} \mathrm{ha}^{-1} \mathrm{ano}^{-1}$, correspondente ao ponto de mínima, onde ocorre a menor perda de COT (Figura 1b).

A redução das perdas de COT com o incremento da dose de dejeto até $120 \mathrm{~m}^{3} \mathrm{ha}^{-1} \mathrm{ano}^{-1}$ é atribuída a melhorias na qualidade estrutural e hidráulica do solo (Mellek et al., 2010) e à menor perda de água e sedimento por escoamento superficial (Silveira, 2009). Em estudo paralelo no mesmo experimento, foi verificado que a aplicação de dejeto melhora algumas características estruturais e hidráulicas desse solo, como macroporosidade, estabilidade de agregados, taxa de infiltração de água e sortividade (Mellek et al., 2010). Tais melhorias reduziram em $69 \%$ a perda de água e em $83 \%$ a perda de sedimento por escoamento superficial com a dose de $120 \mathrm{~m}^{3} \mathrm{ha}^{-1}$ ano $^{-1}$ (Silveira, 2009), explicando, portanto, as menores perdas de $\mathrm{C}$ com a aplicação de dejeto.

A dose de dejeto normalmente utilizada pelos produtores dos Campos Gerais do Paraná encontra-se em torno de $60 \mathrm{~m}^{3} \mathrm{ha}^{-1} \mathrm{ano}^{-1}$. Com base nos resultados, pode-se inferir, portanto, que a dose de aplicação de dejeto empregada atualmente nas áreas de plantio direto da região está contribuindo para a diminuição das perdas de COT por escoamento. Considerando somente a perda de COT, haveria a possibilidade inclusive de aumentar a dose de aplicação, porém essa recomendação não é prudente
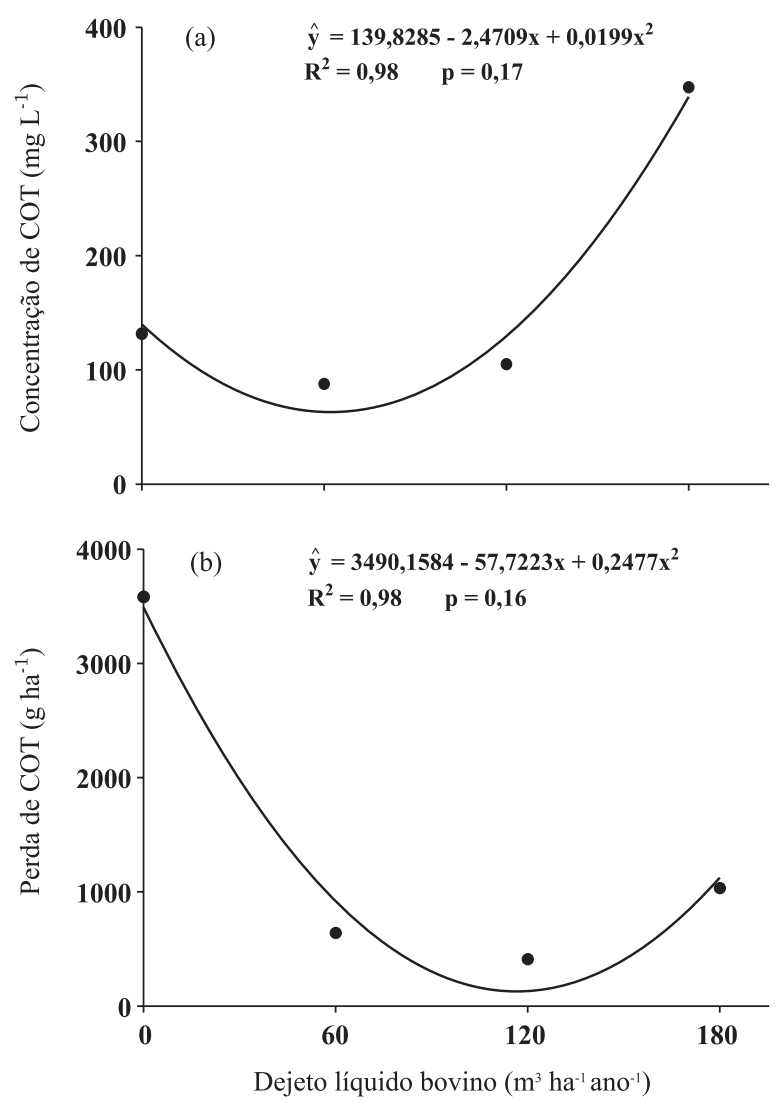

Figura 1. Concentração média ponderada de carbono orgânico total (COT) (a) e perda acumulada de COT (b) em escoamento superficial sob chuva natural após a aplicação de doses de dejeto líquido bovino em Latossolo franco-argiloarenoso manejado sob plantio direto. Ponta Grossa-PR. Avaliações de novembro de 2005 a maio de 2008 .

ainda e estudos complementares necessitam ser realizados no sentido de confirmar os resultados deste estudo e incluir outras variáveis relacionadas com impactos ambientais da aplicação de dejeto, como a lixiviação de $\mathrm{N}-\mathrm{NO}_{3}{ }^{-}$e a emissão de óxido nitroso.

A quantidade acumulada de COT perdida durante o período de avaliação variou de aproximadamente 0,4 a 3,6 kg ha-1 (Figura 1b), valores considerados baixos. Essas perdas são comparáveis com as reportadas em outros estudos de escoamento superficial realizados em manejo conservacionista (Bertol et al., 2004; Santos et al., 2007). Tais estudos, no entanto, foram feitos sob chuva simulada de aproximadamente $1 \mathrm{~h}$ de duração e logo após a aplicação do dejeto. Neste trabalho, as perdas de COT referem-se a um período de dois anos e sete meses, com chuvas naturais ocorridas no mínimo dez dias após a aplicação do dejeto.

A implicação negativa do transporte de C orgânico das áreas agrícolas para os cursos de água é devida ao fato de esse elemento servir como substrato ao desenvolvimento de organismos heterotróficos aquáticos e, por isso, ter relação direta com o oxigênio 
dissolvido. Por aumentar a disponibilidade de $\mathrm{N}$ e $\mathrm{P}$ por meio da mineralização, participa também do processo de eutrofização (Eghball et al., 2002). Especificamente, a presença de C orgânico solúvel é preocupante em reservatórios de água para abastecimento humano, devido à formação de compostos cancerígenos (Kay et al., 2009).

O C perdido no escoamento superfical do tratamento sem aplicação de dejeto se deve ao material vegetal existente no solo em decomposição (Leite et al., 2004), uma vez que essa área se encontra em plantio direto há vários anos e, também, há perda do $\mathrm{C}$ associado às partículas do solo contidas no escoamento superficial. Elevados teores de C orgânico na superfície do solo são comuns em sistema de plantio direto (Schick et al., 2000). Nos tratamentos com aplicação de dejeto, além da matéria orgânica do solo, foi depositada sobre a superfície do solo uma camada de matéria orgânica provinda do dejeto. No entanto, no tratamento sem adição de dejeto observam-se valores maiores de quantidade perdida de C (Figura 1b), o que se justifica pela maior perda de sedimento e de água nesse tratamento, conforme verificou Silveira (2009). O volume de água perdido em todo o período foi de 1,8; 0,8; 0,6; e 0,4 mm, e o de solo, de 49, 18, 7 e $3 \mathrm{~kg} \mathrm{ha}^{-1}$, respectivamente nas doses de $0,60,120$ e $180 \mathrm{~m}^{3} \mathrm{ha}^{-1}$ ano $^{-1}$ (Silveira, 2009). Dessa forma, é importante ressaltar que, apesar de a perda de água ser menor no tratamento com $180 \mathrm{~m}^{3} \mathrm{ha}^{-1} \mathrm{ano}^{-1}$ de dejeto, a perda de $\mathrm{C}$ foi maior, mostrando a grande contribuição da concentração do elemento.

\section{Nitrogênio solúvel}

A concentração média ponderada de $\mathrm{N}-\mathrm{NO}_{3}{ }^{-}$não foi afetada pela aplicação de dejeto (Figura 2a) e mesmo no tratamento com $180 \mathrm{~m}^{3} \mathrm{ha}^{-1} \mathrm{ano}^{-1}$, que teve a maior concentração (3,5 $\left.\mathrm{mg} \mathrm{L}^{-1}\right)$, esteve abaixo do limite máximo (10 $\left.\mathrm{mg} \mathrm{L}^{-1}\right)$ determinado pela Resolução do CONAMA 357 (Brasil, 2005) e pela Portaria do Ministério da Saúde 548 (Brasil, 2004). Esses resultados indicam a grande capacidade de infiltração de $\mathrm{N}^{-\mathrm{NO}_{3}}$ - (Eghball \& Gilley, 1999; Guadagnin et al., 2005; Piovesan et al., 2009), diminuindo, assim, o escoamento superficial desse poluente. No entanto, se por um lado não existe evidente problema com poluição de nitrato nas águas superficiais, por outro isso pode estar ocorrendo nas águas subsuperficias. É importante salientar que, neste estudo, não foram avaliadas as perdas por lixiviação, o que pode ser um grande problema, considerando-se as elevadas doses utilizadas, a textura franco-argiloarenosa do solo e o sistema plantio direto, que, pelo não revolvimento do solo, favorece a formação de fluxo preferencial (Simard et al., 2000).

As concentrações de $\mathrm{N}^{-\mathrm{NH}_{4}}{ }^{+}$aumentaram com a aplicação de dejeto (Figura 2b), o que era esperado, em razão de ser essa a principal forma de $\mathrm{N}$ solúvel encontrada em resíduos líquidos de animais (Hooda et al., 2000). Os valores médios ponderados oscilaram de 5,9 a 13,1 $\mathrm{mg} \mathrm{L}^{-1}$ (Figura 2b), ultrapassando o limite máximo $\left(3,7 \mathrm{mg} \mathrm{L}^{-1} \mathrm{de} \mathrm{N}-\mathrm{NH}_{4}{ }^{+}\right.$para $\mathrm{pH}$ da água inferior a 7,5) estabelecido pelo CONAMA 375 (Brasil, 2005) e indicando um potencial poluidor dessa forma de $\mathrm{N}$ caso este alcance os corpos d'água.

$\mathrm{O} \mathrm{N}-\mathrm{NH}_{4}{ }^{+}$apresentou concentrações superiores ao $\mathrm{N}-\mathrm{NO}_{3}$ - (Figuras 2b), concordando com os resultados encontrados por Smith et al. (2001a), cuja concentração máxima em experimento de longa duração com dejeto líquido bovino foi de $30 \mathrm{mg} \mathrm{L}^{-1}$. Analisando a contribuição de $\mathrm{N}-\mathrm{NO}_{3}{ }^{-}$e $\mathrm{N}-\mathrm{NH}_{4}{ }^{+}$ (Figura 3), percebeu-se que a fração $\mathrm{N}-\mathrm{NH}_{4}{ }^{+}$ apresentou a maior percentagem, principalmente nos tratamentos que receberam dejeto líquido bovino. Fica, então, a preocupação em relação à entrada desse nutriente via escoamento nos rios ou lagos, principalmente como citado anteriormente, por apresentar suas concentrações acima do limite máximo permitido pela legislação.

Levando em consideração a quantidade aplicada de $\mathrm{N}$ via dejeto, esperava-se que as concentrações e as perdas acumuladas aumentassem com o incremento das doses. No entanto, a quantidade perdida de $\mathrm{N}$ teve redução com a elevação das doses de dejeto bovino
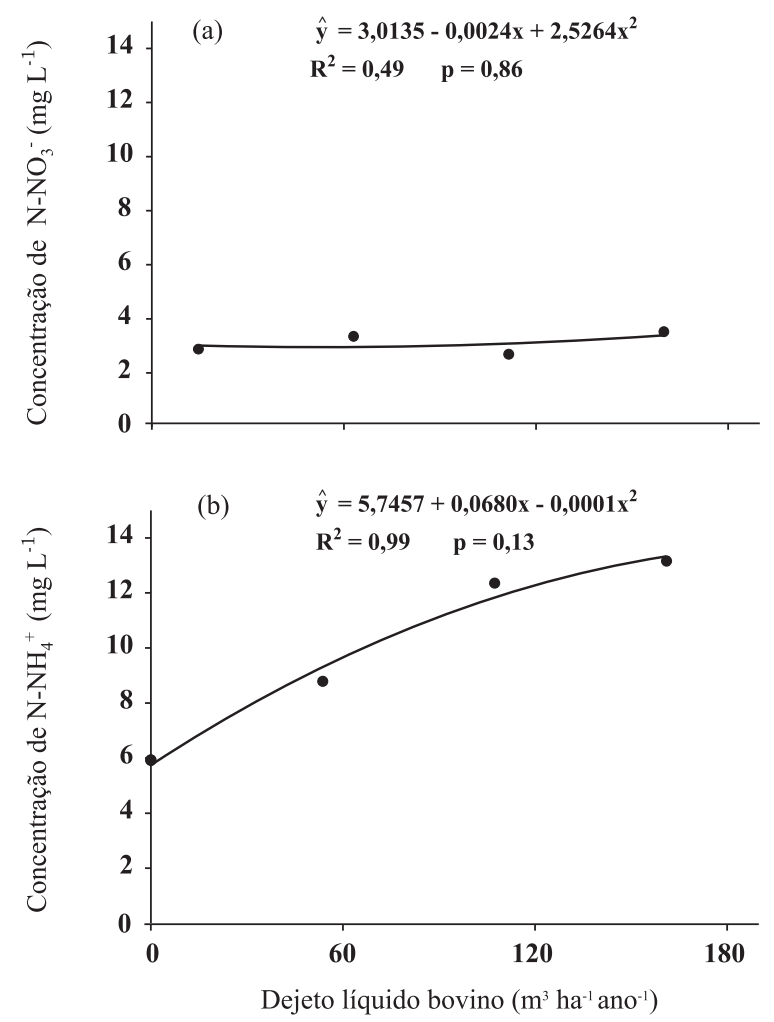

Figura 2. Concentrações médias ponderadas de N$\mathrm{NO}_{3}^{-}$(a) e N-NH${ }_{4}^{+}$(b) em escoamento superficial sob chuva natural após a aplicação de doses de dejeto líquido bovino em Latossolo francoargiloarenoso manejado sob plantio direto. Ponta Grossa-PR. Avaliações de novembro de 2005 a maio de 2008. 


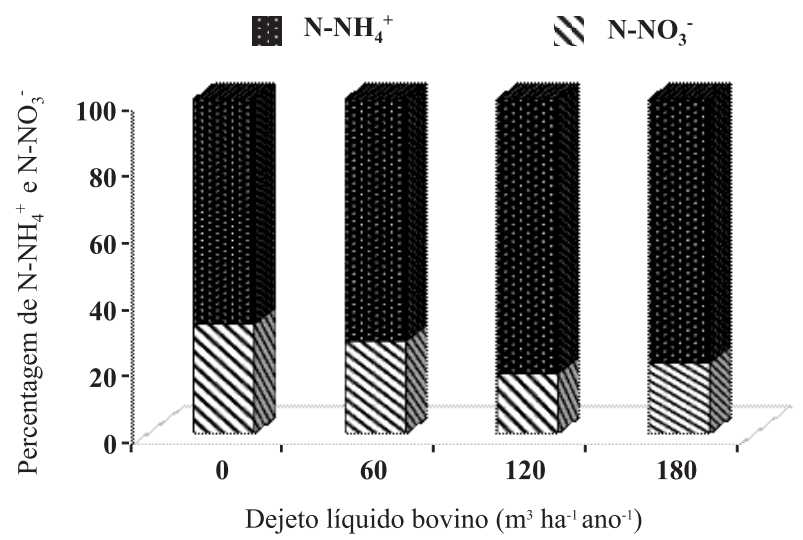

Figura 3. Distribuição da concentração média ponderada de $\mathrm{N}^{-\mathrm{NO}_{3}}{ }^{-}$e $\mathrm{N}-\mathrm{NH}_{4}$ em escoamento superficial sob chuva natural após a aplicação de doses de dejeto líquido bovino em Latossolo franco-argiloarenoso manejado sob plantio direto. Ponta Grossa-PR. Avaliações de novembro de 2005 a maio de 2008.

(Figura 4), mostrando a maior contribuição do volume de escoamento comparada à concentração do elemento. Vários autores (Basso, 2003; Bertol et al., 2005; Peles, 2007; Mori, 2008) encontraram maiores perdas de N via escoamento com a aplicação de dejeto, mostrando o efeito do selamento superficial promovido pelo dejeto. Esses resultados são de experimentos de curto prazo, com chuva simulada logo após a aplicação de dejeto na superfície. No entanto, em experimento de longa duração, Smith et al. (2001a) observaram menores perdas de $\mathrm{N}$, justificadas pelo efeito positivo do dejeto na estrutura do solo, melhorando a taxa de infiltração do solo e, assim, diminuindo o escoamento superficial (Mellek et al., 2010).

Nas parcelas que não receberam o dejeto líquido bovino, a perda acumulada de $\mathrm{N}-\mathrm{NH}_{4}{ }^{+}$mais $\mathrm{N}-\mathrm{NO}_{3}$. (Figura 4) foi de $124 \mathrm{~g}^{-1}$, aproximadamente 0,06\% do $\mathrm{N}$ aplicado via adubação mineral. Para a maior dose de dejeto, a perda de $\mathrm{N}-\mathrm{NH}_{4}{ }^{+}$mais $\mathrm{N}-\mathrm{NO}_{3}$ - foi próxima de $63 \mathrm{~g} \mathrm{ha}^{-1}$, sendo referente a 0,01 do total aplicado via adubação mineral e dejeto líquido bovino. Essas perdas são consideradas pequenas e não são significativas em termos agronômicos, no entanto ambientalmente podem causar sérios problemas e, portanto, mesmo havendo redução dessas perdas com a adição de dejeto, outras práticas conservacionistas são importantes, principalmente as que evitem a entrada do escoamento provindo da lavoura diretamente nos cursos de água.

\section{CONCLUSÕES}

1. A aplicação de até $120 \mathrm{~m}^{3} \mathrm{ha}^{-1} \mathrm{ano}^{-1}$ de dejeto líquido bovino em solo franco-argiloarenoso manejado sob plantio direto reduziu as perdas de C orgânico e N por escoamento superficial, com consequências
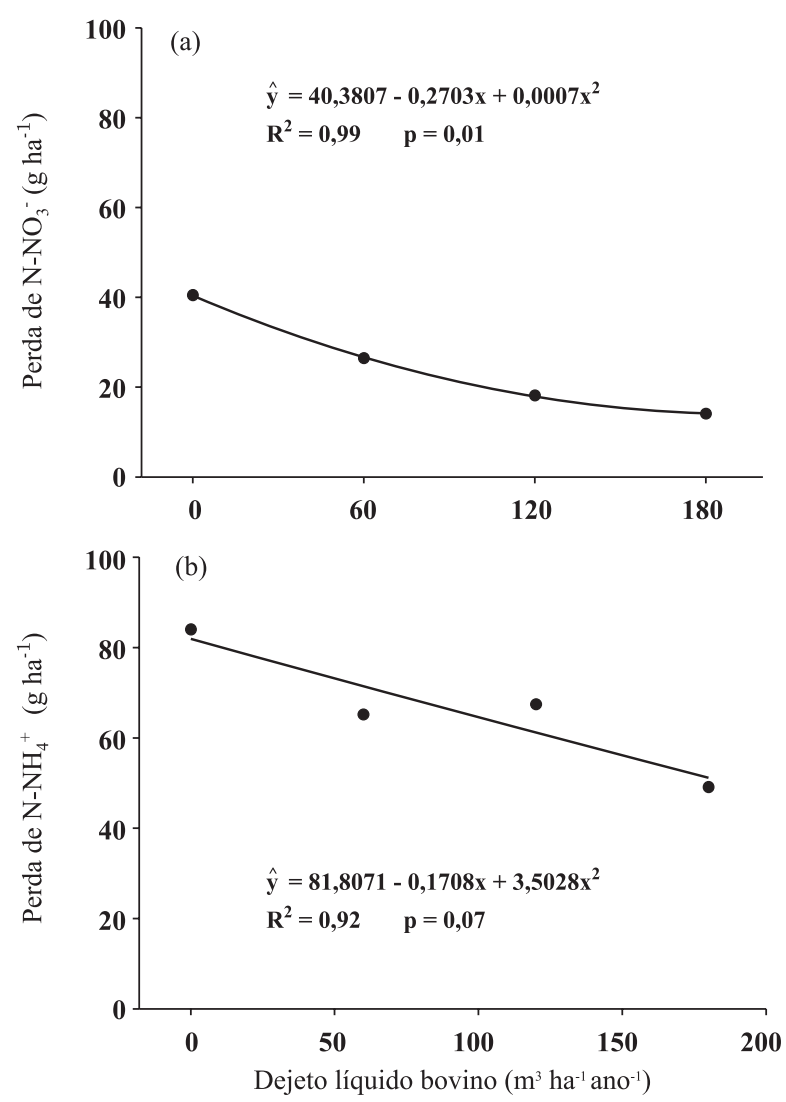

Figura 4. Perda acumulada de $\mathrm{N}_{-} \mathrm{NO}_{3}{ }^{-}$(a) e $\mathrm{N}_{-} \mathrm{NH}_{4}^{+}$ (b) em escoamento superficial sob chuva natural após a aplicação de doses de dejeto líquido bovino em Latossolo franco-argiloarenoso manejado sob plantio direto. Ponta Grossa-PR. Avaliações de novembro de 2005 a maio de 2008.

positivas para a qualidade da água em corpos hídricos a jusante. Porém, dose superior tende a aumentar a concentração dos referidos elementos e, por conseguinte, diminuir a qualidade da água.

2. As concentrações médias ponderadas de $\mathrm{N}-\mathrm{NO}_{3}$. estiveram abaixo do limite permitido pela legislação brasileira, porém as de $\mathrm{N}-\mathrm{NH}_{4}{ }^{+}$ficaram acima do máximo permitido, indicando a necessidade de práticas de controle e retenção do escoamento superficial para evitar a entrada desse elemento nos corpos d'água, mesmo em áreas sob plantio direto.

\section{LITERATURA CITADA}

ALLEN, B.L. \& MALLARINO, A.R. Effect of liquid swine manure rate, incorporation, and timing of rainfall on phosphorus loss with surface runoff. J. Environ. Qual., 37:125-137, 2008.

APHA. Standard methods for the examination of water and wastewater. 19.ed. Washington, 1995. 1368p. 
BASSO, C. Perdas de nitrogênio e fósforo com aplicação no solo de dejetos líquidos de suínos. Santa Maria, Universidade Federal de Santa Maria, 2003. 98p. (Tese de Doutorado)

BERTOL, I.; COGO, N.P. \& LEVIEN, R. Erosão hídrica em diferentes preparos do solo logo após as colheitas de milho e trigo, na presença e na ausência dos resíduos culturais. R. Bras. Ci. Solo, 21:409-418, 1997.

BERTOL, I.; LEITE, D.; GUADAGNIN, J.C. \& RITTER, S.R. Erosão hídrica em um Nitossolo Háplico submetido a diferentes sistemas de manejo sob chuva simulada. II perdas de nutrientes e carbono orgânico. R. Bras. Ci. Solo, 28:1045-1054, 2004.

BERTOL, I.; MELLO, E.L.; GUADAGNIN, J.C.; ZAPAROLLI, A.L.V. \& CARRAFA, M.R. Nutrient losses by water erosion. Sci. Agric., 60:581-586, 2003.

BERTOL, O.J.; RIZZI, N.E.; BERTOL, I. \& ROLOFF, G. Perdas de solo e água e qualidade do escoamento superficial associadas à erosão entre sulcos em área cultivada sob semeadura direta e submetida às adubações mineral e orgânica. R. Bras. Ci. Solo, 31:781-792, 2007.

BERTOL, O.J.; RIZZI, N.E.; FAVARETTO, N. \& LAVORANTI, O.J. Perdas de nitrogênio via superfície e subsuperfície em sistema de semeadura direta. R. Flor., 35:429-443, 2005 .

BOYD, C. \& TUCKER, C. Water quality and pond soil analyses for aquaculture. Alabama, Auburn university, 1992.

BRASIL. Conselho Nacional do Meio Ambiente - CONAMA. Resolução CONAMA n ${ }^{\circ}$. 357. Diário Oficial da União de 18/03/2005. Brasília, 2005.

BRASIL. Ministério da Saúde. Portaria MS nº. 518/2004. Secretaria de Vigilância em Saúde, Coordenação-Geral de Vigilância em Saúde Ambiental. Brasília, 2004.

BUNDY, L.G.; ANDRASKI, T.W. \& POWELL, J.M. Management practice effects on phosphorus losses in runoff in corn production systems. J. Environ. Qual., 30:1822-1828, 2001

CAVIGLIONE, J.H.; KIIHL, L.R.B.; CARAMORI, P.H. \& OLIVEIRA, D. Cartas climáticas do Paraná. Londrina, IAPAR, 2000. CD ROM.

COGO, N.P.; FOSTER, G.R. \& MOLDENHAUER, W.C. Flow rates-soil erosion relationships as affected by wheat residue cover: An attempt to define slope-length limits for conservation tillage. R. Bras. Ci. Solo, 20:475-483, 1996.

CORRELL, D.L. The role of phosphorus in the eutrophication of receiving waters: A review. J. Environ. Qual., 27:261$266,1998$.

DANIEL, T.C.; SHARPLEY, A.N. \& LEMUNYON, J.L. Agricultural phosphorus and Eutrophication: A Symposium Overview. J. Environ. Qual., 27:251-257, 1998.
DINNES, D.L.; KARLEN, D.L.; JAYNES, D.B.; KASPAR, T.C.; HATFIELD, J.L.; COLVIN,T. S. \& CAMBARDELLA, C.A. Nitrogen management strategies to reduce nitrate leaching in tiledrained midwestern soils. Agron. J., 94:153171,2002

EGHBALL, B. \& GILLEY, J.E. Phosphorus and nitrogen in runoff following beef cattle manure or compost application. J. Environ. Qual., 28:1201-1210, 1999.

EGHBALL, B.; WIENHOLD, B.J.; GILLEY, J.E. \& EIGENGERG, R.A. Mineralization of manure nutrients. J. Soil Water Conserv., 57:470-473, 2002

EMPRESA BRASILEIRA DE PESQUISA AGROPECUÁRIA EMBRAPA. Mapa do levantamento semidetalhado de solos: Municipio de Castro. Castro, Fundação ABC, 2001.

GUADAGNIM, J.C.; BERTOL, I.; CASSOL, P.C. \& AMARAL, A.J. Perdas de solo, água e nitrogênio por erosão hídrica em diferentes sistemas de manejo. R. Bras. Ci. Solo, 29:277-286, 2005

HOODA, P.S.; EDWARDS, A.C.; ANDERSON, H.A. \& MILLER, A. A review of water quality concerns in livestock farming areas. Sci. Total Environ., 250:143-147, 2000.

KAY, P.; EDWARDS, A.C. \& FOULGER, M. A review of the efficacy of contemporary agricultural stewardship measures for ameliorating water pollution problems of key concern to the UK water industry. Agric. Syst., 99:67$75,2009$.

LEITE, D.; BERTOL, I.; GUADAGNIN, J.C.; SANTOS, E.J. \& RITTER, S.R. Erosão hídrica em um Nitossolo Háplico submetido a diferentes sistemas de manejo sob chuva simulada. I - Perdas de solo e água. R. Bras. Ci. Solo, 28:1033-1044, 2004.

MELLEK, J.E.; DIECKOW, J.; SILVA, V.L.; FAVARETTO, N.; PAULETTI, V.; VEZZANI, F.M. \& SOUZA, J.L. Dairy liquid manure and no-tillage: Physical and hydraulic properties and carbon stocks in a Cambisol of Southern Brazil. Soil Till. Res., 2010. (No Prelo)

MELLO, E.L.; BERTOL, I.; ZAPAROLLI, A.L.V. \& CARRAFA, M.R. Perdas de solo e água em diferentes sistemas de manejo de um Nitossolo Háplico submetido à chuva simulada. R. Bras. Ci. Solo, 27:901-909, 2003.

MORI, H.F. Perdas de solo, água e nutrientes em sistema de plantio direto sob aplicação de dejeto líquido de bovinos e chuva simulada. Curitiba, Universidade Federal do Paraná, 2008. 65p. (Tese de Mestrado)

MORI, H.F.; FAVARETTO, N.; PAULETTI, V.; DIECKOW, J. \& SANTOS, W.L. Perda de água, solo e fósforo com aplicação de dejeto líquido bovino em latossolo sob plantio direto e com chuva simulada. R. Bras. Ci. Solo, 33:89-198, 2009 .

PELES, D. Perdas de solo, água e nutrientes sob aplicação de gesso e dejeto líquido de suínos. Curitiba, Universidade Federal do Paraná, 2007. 84p. (Tese de Mestrado)

PIOVESAN, R.P.; FAVARETTO, N.; PAULETTI, V.; MOTTA, A.C.V. \& REISSMANN, C.B. Perdas de nutrientes via subsuperfície em colunas de solo sob fertilização mineral e orgânica. R. Bras. Ci. Solo, 33:757-766, 2009. 
SANTOS, T.E.M.; MONTENEGRO, A.A.; SILVA, E.F.F.; LIMA NETO, J.A. Perdas de carbono orgânico, potássio e solo em Neossolo Flúvico sob diferentes sistemas de manejo no semi-árido. R. Bras. Ci. Agr., 2:143-149, 2007.

SCHERER, E.E. \& AITA, C. Avaliação da qualidade do dejeto líquido de suíno da região oeste catarinense para fins de utilização como fertilizante. Florianópolis, EPAGRI, 1996. (Boletim Técnico, 79)

SCHICK, J.; BERTOL, I.; BATISTELA, O. \& BALBINOT, J.A.A Erosão hídrica em Cambissolo Húmico alumínico submetido a diferentes sistemas de preparo e cultivo do solo. II - Perdas de nutrientes e carbono orgânico. R. Bras. Ci. Solo, 24:437-447, 2000.

SHARPLEY, A.N.; SMITH, S.J. \& NANEY, J.W Environmental impact of agricultural nitrogen and phosphorus use. J. Agric. Food. Chem., 35:812-817, 1987.

SILVEIRA, F.M. Perda de solo, água e nutrientes com aplicação de dejeto líquido bovino em latossolo franco-argilo arenoso sob plantio direto e chuva natural. Curitiba, Universidade Federal do Paraná, 2009. 95p. (Tese de Mestrado)
SIMARD, R.R.; BEAUCHEMIN, S. \& HAYGARTH, P.M. Potential for preferential pathways of phosphorus transport. J. Environ. Qual., 29:97-105, 2000.

SMITH, K.A.; JACKSON, D.R. \& PEPPER, T.J. Nutrient losses by surface run-off following the application of organic manures to arable land. 1. Nitrogen. Environ. Poll., 112:41$51,2001 \mathrm{a}$.

SMITH, K.A.; JACKSON, D.R. \& WITHERS, P.J.A. Nutrient losses by surface run-off following the application of organic manures to arable land. 2. Phosphorus. Environ. Poll., 112:53-60, 2001b.

SMITH, S.J.; SCHEPERS, J.S. \& PORTER, L.K. Assessing and managing agricultural nitrogen losses to the environment. In: STEWART, B.A., ed. Advances in soil science. Chelsea, Lewis Publishers, 1990. v.14. p.1-43.

SPARKS, D.L. Environmental soil chemistry. San Diego, Academic Press, 1995. 267p.

SYSTAT SOFTWARE. Scientific Graphing Software: Sigma Plot, versão 10.0. San Rafael, Hearne Scientific Software, 2006. 
